\title{
Segurança \\ nos Laboratórios
}

\section{Acetaldeído (etanal)}

$\mathrm{O}$ acetaldeído é um líquido incolor de cheiro penetrante a frutos, p. e. $21^{\circ} \mathrm{C}$, miscível com a água.

É uma substância extremamente inflamável, que pode formar peróxidos explosivos, e libertar vapor tóxico que irrita os olhos e o aparelho respiratório. Evitar o contacto com os olhos e a inalação do vapor. VLT 100 ppm (180 $\mathrm{mg} \mathrm{m}^{-3}$ ).

Efeitos tóxicos: O vapor irrita os olhos e causa dores de cabeça e tonturas. O líquido, quando ingerido, provoca irritação grave do aparelho digestivo.

Reacções perigosas: $\mathrm{O}$ acetaldeído é extremamente reactivo com anidridos de ácidos, álcoois, halogéneos, cetonas, fenóis, aminas, amoníaco, cianeto de hidrogénio e sulfureto de hidrogénio. Polimeriza exotermicamente com ácido acético. Pode provocar incêndio e explosão com ar, oxigénio e peróxido de hidrogénio.

Perigo de incêndio: Ponto de fulgor: $-38^{\circ} \mathrm{C}$; limites de explosividade $4-57 \%$; temperatura de autoignição: $185^{\circ} \mathrm{C}$. Extintores: água, pó químico seco, neve carbónica ou líquido vaporizante.

Eliminação de resíduos: Eliminar todas as possíveis fontes de ignição. Manter as pessoas afastadas do local afectado. Usar máscara respiratória e luvas. Deitar fora diluindo com muita água corrente. Ventilar muito bem a zona afectada para evaporar o líquido restante e remover o vapor.

\section{Cloreto de acetilo}

O cloreto de acetilo é um líquido incolor volátil, fumante, de cheiro pungente, p.e. $51^{\circ} \mathrm{C}$, que se decompõe rapidamente com a água formando ácido clorídrico e ácido acético. É uma substância muito inflamável, que provoca queimaduras e irrita a pele, os olhos e o aparelho respiratório. Evitar inalar o vapor e o contacto com os olhos e a pele.

Efeitos tóxicos: O vapor irrita gravemente os olhos e todas as partes do aparelho respiratório. O líquido provoca queimaduras nos olhos e na pele. Se ingerido, provoca de imediato lesões internas graves.

Reacções perigosas: Reage violentamente com água e sulfóxido de dimetilo (DMSO). Pode decompor violentamente ao ser preparado a partir de tricloreto de fósforo e ácido acético.

Perigo de incêndio: Ponto de fulgor: $4^{\circ} \mathrm{C}$; temperatura de autoignição: $390^{\circ} \mathrm{C}$. Extintores: espuma, pó químico seco, neve carbónica ou líquido vaporizante.

Eliminação de resíduos: Eliminar todas as possíveis fontes de ignição. Manter as pessoas afastadas do local afectado. Usar máscara respiratória e luvas. Misturar com excesso de carbonato de sódio e lavar cuidadosamente com água. Deitar fora, diluindo com muita água corrente.

\section{Cloreto de alumínio anidro}

O cloreto de alumínio anidro apresenta-se sob a forma de pedaços, grânulos ou pó amarelo ou esbranquiçado; decompõe-se violentamente na presença de água com formação de cloreto de hidrogénio.

É uma substância que provoca queimaduras e irrita a pele, os olhos e o aparelho respiratório. Evitar inalar a poeira e o contacto com a pele e os olhos.

Efeitos tóxicos: A inalação da poeira causa irritação ou queimaduras nas mucosas. $\mathrm{O}$ contacto com os olhos provoca queimaduras dolorosas. Quando a pele está húmida, produz-se calor por contacto, resultando queimaduras térmicas e químicas. Quando ingerido, provoca imediatamente lesões graves.

Reaç̧ões perigosas: Reage violentamente com água, óxido de etileno, e nitrobenzeno/fenol.

Eliminação de resíduos: Usar protecção facial e luvas. Misturar com areia seca, colocar num balde seco, transportar para local seguro no exterior e adicionar a mistura; em pequenas quantidades de cada vez, a um grande volume de água. Terminada a reacção, deitar fora, diluindo com muita água corrente.

\section{Amoníaco (gás)}

O amoníaco é um gás incolor de cheiro penetrante, p.e. $-33^{\circ} \mathrm{C}$, fornecido em cilindros sob a forma de um líquido sob pressão.

É uma substância tóxica por inalação, que irrita a pele, os olhos e o aparelho respiratório. Evitar inalar o gás, VLT $25 \mathrm{ppm}\left(18 \mathrm{mg} \mathrm{m}^{-3}\right)$.

Efeitos tóxicos: O gás irrita os olhos e o aparelho respiratório.

\footnotetext{
aNETI - Departamento de Tecnologia de Indústria Química, Estrada das Palmeiras - 2795 Queluz.
} 
Reacções perigosas: Misturas de amoníaco e ar podem explodir. Reage violentamente ou com formação de produtos explosivos com halogéneos e compostos interhalogenados. Reage violentamente com haletos de boro. Provoca a polimerização explosiva do óxido de etileno. Forma compostos explosivos com mercúrio e compostos de prata.

Perigo de incêndio: Limites de explosividade 16-25\%; temperatura de autoignição: $651^{\circ} \mathrm{C}$. Sendo fornecido em cilindros, deve fechar-se a respectiva válvula e transportar o cilindro para fora do local do incêndio.

Eliminação de resíduos: Excesso de gás ou fugas de cilindros devem ser conduzidas através de uma coluna de lavagem com circulação de água ou para uma hote equipada com este sistema.

\section{Amónia (soluções)}

A amónia é geralmente fornecida como uma solução aquosa $35 \%$ (densidade específica 0,88 ). Em tempo quente, esta solução cria pressão na respectiva embalagem, pelo que a tampa deve ser aberta com cuidado.

Esta solução provoca queimaduras e irrita os olhos, a pele e o aparelho respiratório. Evitar inalar o vapor e o contacto da solução com os olhos e a pele, VLT $25 \mathrm{ppm}$ (18 $\mathrm{mg} \mathrm{m}^{-3}$ ).

Efeitos tóxicos: O vapor irrita o aparelho respiratório. A solução causa queimaduras graves nos olhos e queima a pele. Se ingerida, a solução provoca lesões internas graves.

Eliminação de resíduos: Usar óculos de protecção e luvas, e botas de borracha se o derrame for grande. Lavar com muita água e deitar fora diluindo com muita água corrente. Ventilar bem o local.

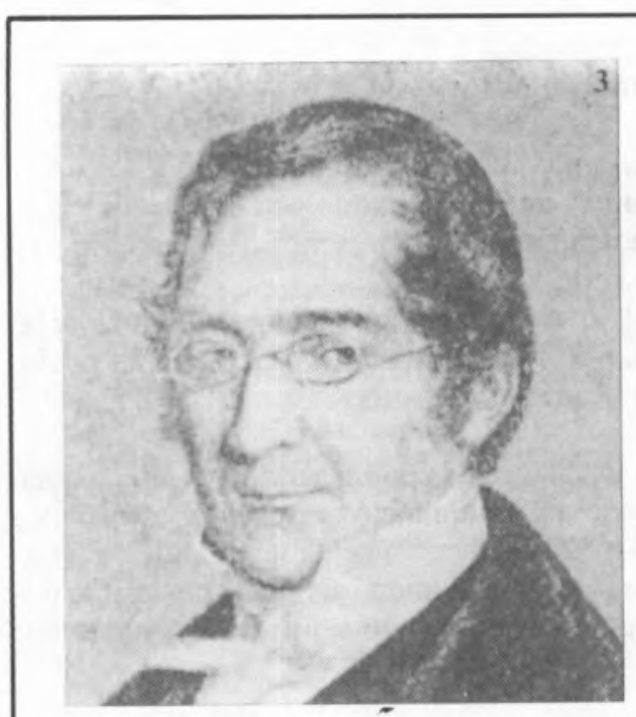

GAY-LUSSAC, Joseph (1778-1850)
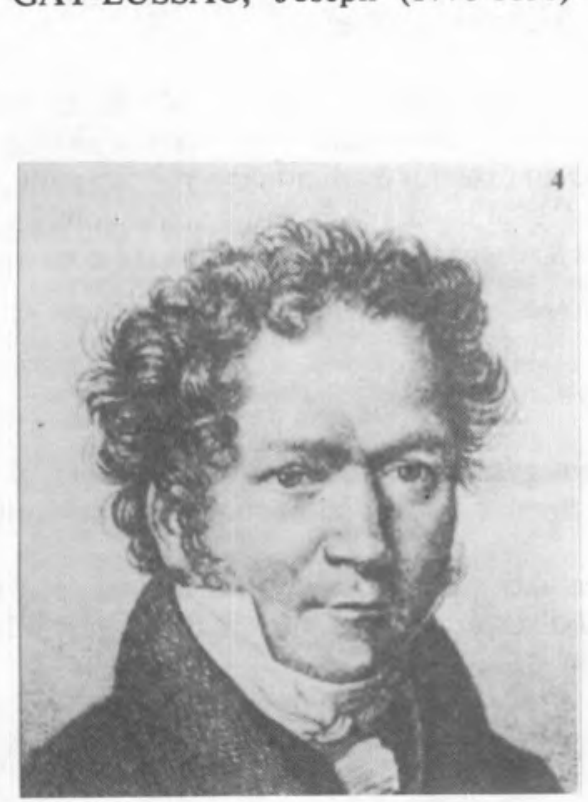

THENARD, Louis, Barão (1777-1857)
1809

Gay-Lussac e Thenard comprovaram o enxofre como sendo um elemento, refutando trabalhos anteriores de químicos como Davy que o consideravam um composto.

Gay-Lussac estabelece que na combinação de dois gases os volumes envolvidos estão numa razão de números pequenos e inteiros. Dalton, que considerava pesos e não volumes, refutou esta conclusão, mais tarde largamente aceite sob o nome de lei de Gay-Lussac.

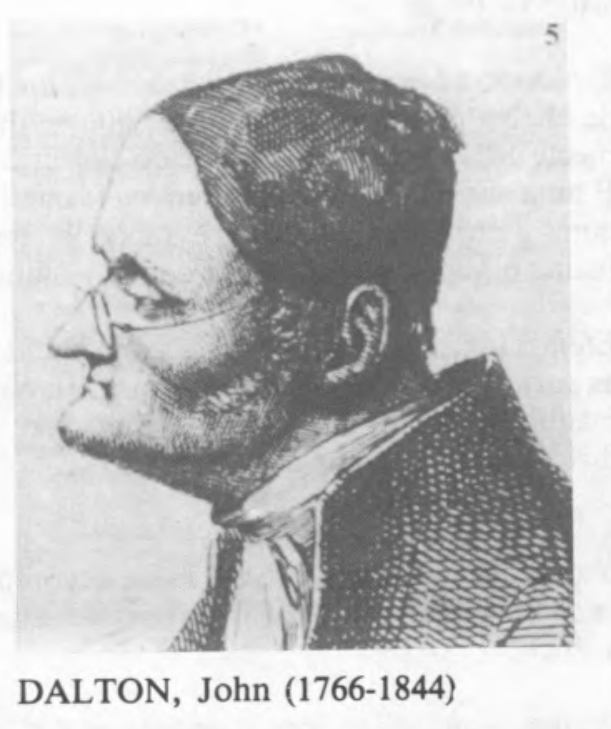

